\title{
MEASURING CONSUMER-BASED BRAND AUTHENTICITY
}

\begin{abstract}
Postmodern consumers use brands to create an authentic self and to reconnect to place, time, culture and others. Although previous research has identified that consumers draw on a range of cues in order to attribute authenticity to branded objects, no scales exist to measure the construct of brand authenticity. Building on the existing literature, this paper uses quantitative methods to develop a psychometrically robust measure of brand authenticity from a consumer's perspective. Findings demonstrate convergent, discriminant and predictive validity, whereby 14 items represent three interrelated first order factors labeled quality commitment, sincerity and heritage that correspond with a higher order brand authenticity construct. This study extends our understanding of the consumption of authenticity. Moreover, it provides a tool by which firms can evaluate the effectiveness of strategic decisions designed to deliver an authentic brand offering to consumers. Limitations and directions for future research are discussed.
\end{abstract}

Keywords: Authenticity; Branding; Consumer Behavior; Scale Development. 


\section{MEASURING CONSUMER-BASED BRAND AUTHENTICITY}

\section{BACKGROUND}

Postmodern markets are characterized by a brand-dominated hyperreality where consumers struggle to differentiate between the 'real' and 'fake' (Arnould \& Price, 2000; Firat \& Venkatesh, 1995). While authenticity has historically been associated with transcending the self and the market (Beverland, 2005; Fine, 2003; Kozinets, 2002; Peterson, 2005; Taylor, 1992; Thompson, Rindfleisch, \& Arsel, 2006), an emerging stream of consumer research identifies that people attribute authenticity to brands. Research suggests that authenticity is central to brand status, equity and corporate reputation (Beverland, 2005; Gilmore \& Pine, 2007), with some even suggesting it is one of the "cornerstones of contemporary marketing", (Brown, Kozinets \& Sherry, 2003, p. 21). The concept itself, however, is still not well understood nor clearly defined (Grayson \& Martinec, 2004; Rose \& Wood, 2005).

Extant research has examined (to various extents) consumers' quests for authentic experiences (Arnould \& Price, 2000), rituals associated with the authentic self (Belk \& Costa, 1998; Kozinets, 2002), the cues used to attribute authenticity to objects (Beverland, Lindgreen, \& Vink, 2008; Grayson \& Martinec, 2004; Leigh, Peters \& Shelton, 2006; Thompson et al., 2006), the processes used to assess an object's authenticity (Rose \& Wood, 2005), and the various forms authenticity can take (Brown et al., 2003; Grayson \& Martinec, 2004). More recently, research has focused on the effects of brand authenticity on brand trust and SME growth (Eggers, O’Dwyer, Kraus, Vallaster and Guldenberg 2012) and its role in establishing and maintaining brand auras (Alexander 2009) from the perspective of key stakeholders within an organization (ie. CEOs, marketing specialists). Eggers et.al. (2012) conclude that brand authenticity has a significant impact on brand trust and can help fuel firm growth within the market place. However, it is important for the organization as a whole to embrace a culture that encourages, fosters and enhances authentic values. 
We extend this line of inquiry through the development of a consumer-based brand authenticity (CBBA) scale, building on calls for an objective measure of brand authenticity that includes the voice of the consumer (Eggers et.al. 2012). Understanding the outcomes of authenticity for a consumer is important because the search for authenticity is part of a consumer's identity project and is thus goal-driven (Arnould \& Price, 2000; Belk, Wallendorf, \& Sherry, 1989; Gergen, 1991; Goffman 1959; Lifton, 1993; McCracken, 2005; Thompson, 2000). For example, consumers may desire clear connections between perceptual product cues when forced to quickly make a correct decision (Beverland et al., 2008). Or, certain brand cues may be preferred when consumers attempt to fit in with a wider subcultural community or express their social affiliations (Beverland, Farrelly, \& Quester, 2006; Kates, 2004). Thus, preferencing cues and choosing or rejecting brands is part of an authenticating act (a selfreferential act) or authoritative performance (a collective expression) (Arnould \& Price, 2000).

This study also aims to reduce the present fragmentation of research on the consumption of authenticity, which may assist managers in creating and maintaining a brand's authenticity (Beverland, 2005; Leigh et al., 2006; Peterson, 2005). Understanding perceptions of authenticity may help explain consumers' brand attitudes together with their degree of brand loyalty and also lead to a more effective approach to market segmentation. Moreover, the development of an authenticity scale will enable the relationship between this and other marketing constructs to be assessed. Combined, such insights will provide brand managers with a means to assess the efficacy of strategic communication messages designed to establish a perception of authenticity in the minds of external stakeholders, including consumers (Molleda, 2010).

The article is structured as follows. First, we examine the nature of brand authenticity and its core attributes. Second, we explain our methods and report our results. Finally, we address theoretical and managerial implications, limitations and directions for future research. 


\section{THE NATURE OF BRAND AUTHENTICITY}

In business research, the term authenticity has been used in different ways to imply different meanings (Beverland, 2005). Commonly, authenticity is used to refer to the genuineness, reality or truth of something (Kennick, 1985). It has also been defined in terms of sincerity, innocence and originality (Fine, 2003) and related to concepts such as being natural, honest, simple and unspun (Boyle, 2003). Consumers experience authenticity differently and use a range of cues to evaluate the authenticity of an object, which may be based on their interest in, and knowledge of, a subject (Grazian, 2003). Authenticity judgments may be formed around indexical cues (a factual connection between the object and time) or iconic cues (the extent to which an object or event is a reasonable reconstruction of the past) (Grayson \& Martinec, 2004). The distinction between the authentic and inauthentic tends to be subjective and socially or personally constructed (Grayson \& Martinec, 2004; Leigh et al., 2006). It is a behavior experienced by an individual (Sheldon, Ryan, Rawsthorne, \& Ilardi, 1997) that is self authored (Wild, 1965) and self-determined (Deci \& Ryan, 1991).

Brands can acquire an aura of authenticity through a "...commitment to traditions, a passion for craft and production excellence and the public disavowal of the role of modern industrial attributes and commercial motivations" (Beverland, 2005: p.1008). Authentic brands have clarity of purpose that is sincerely executed (authenticbrandindex.com). They are perceived by consumers to be manufactured by artisans (Beverland, 2006; Fine, 2003) using time honored traditions (Postrel, 2003), hand-made methods and/or natural ingredients (Carroll \& Swaminathan, 2000). Such brands have remained true to their original design, evolving slowly to reflect modern times rather than changing consumer fashions (Beverland, 2006; Beverland et al., 2008). Radical changes to designs can upset or confuse customers and lead to questions about a brand's authenticity (Brown et al., 2003; Kozinets, 2001).

Brands with a sense of history and connection with traditional cultures, customs, regions and beliefs acquire a distinctive identity and nostalgic aura that adds to its authenticity 
(Brown et al., 2003; Chhabra, Healy, \& Sills, 2003; Penaloza, 2000; Postrel, 2003). Nostalgic images reflecting a brand's heritage may have no basis in reality (Beverland et al., 2008; Chhabra et al., 2003; Pocock, 1992), but for consumers the absolute truth of such claims may not matter. Consumers may suspend disbelief (Grayson \& Martinec, 2004), negotiate paradox (Rose \& Wood, 2005) or creatively recombine cues to gain a sense of authenticity (Beverland et al., 2008; Postrel, 2003). Brands with a strong heritage may, over time, become synonymous with certain cultural values and acquire symbolic meaning beyond its original identity, which helps establish a sense of legitimacy and authenticity among target groups (Kates, 2004). Brands such as Nike, Harley Davidson, Mountain Dew, and Corona have tapped into a wider cultural zeitgeist and as a result attained market share, institution-like status and legitimacy (Holt, 2004).

Owners of such brands are thought to be driven by integrity, commitment to quality, a sense of moral virtue, and an intrinsic love of the product rather than an economic agenda (Beverland, 2006; Beverland et al., 2006; Beverland et al., 2008). Beverland's (2005) study of fine wine producers identified that the development of a sincere story consisting of demonstrable referents to place, tradition, and non-commercial values was crucial to conveying brand authenticity. Similarly, Fine's (2003) study of self-taught art identified that authenticity diminished when artists visibly adopted the trappings of the market such as 0800 numbers and deliberate customer targeting. Thompson et al. (2006) note that niche coffee brands gain authenticity by contrasting their operations with large commercial brands such as Starbucks. For such brands, there is often a deliberate decoupling (or downplaying) of their day-to-day operations, marketing strategy and commercial skill from the outward projection of images related to craft production, heritage and tradition (Beverland, 2005; Postrel 2003). Such brands are perceived as being 'above commerce'.

In this study brand authenticity is defined as a subjective evaluation of genuineness ascribed to a brand by consumers. From the extant literature it is evident that the brand 
authenticity construct is multifaceted and built around perceptions of heritage (Brown et al., 2003; Penaloza, 2000; Postrel, 2003), nostalgia (Beverland et al., 2008; Chhabra et al., 2003; Pocock, 1992; Postrel, 2003), cultural symbolism (Belk, 1988; Elliott \& Wattanasuwan, 1998; Holt, 2004; Kates, 2004), sincerity (Beverland, 2005; Fine 2003; Holt, 2002; Thompson et al. 2006; Trilling, 1972; Wipperfurth, 2005), craftsmanship (Beverland, 2006; Carroll \& Swaminathan, 2000; Fine, 2003; Postrel, 2003), quality commitment (Beverland, 2005; Gilmore \& Pine 2007) and design consistency (Beverland, 2006; Beverland et al., 2008; Brown et al., 2003; Kozinets, 2001). In developing a measure of brand authenticity we have used these seven cues as a starting point for generating scale items. We believe consumers use a combination of these cues in making evaluations about a brand's authenticity, suggesting there are multiple pathways by which brand authenticity can be established, which is consistent with the outcomes of the Authentic Brand Index (authenticbrandindex.com). However, as the demarcation between some of these cues is blurred (eg. nostalgia and heritage are related for instance, as well as quality commitment and craftsmanship), we expect broader umbrella themes to emerge that capture the essential elements underpinning consumers' authenticity evaluations.

\section{METHOD AND RESULTS}

The purpose of this research is to develop a psychometrically robust measure of brand authenticity from a consumer's perspective. In so doing, four separate studies were undertaken to generate and refine scale items (Study 1), determine and then confirm the underlying factor structure of brand authenticity (Studies 2 and 3), and finally to test for convergent, discriminant and predictive validity of the scale (Study 4). 


\subsection{Study 1 - Item Generation and Refinement}

Churchill's (1979) scale development paradigm was adopted, using a deductive approach for the generation of scale items (Schwab, 1980). Drawing on the extant literature, an initial list of 157 items/statements was generated reflecting seven dimensions of brand authenticity, namely: brand heritage (26 items), quality commitment (21 items); craftsmanship (14 items); sincerity (43 items); nostalgia (23 items); cultural symbolism (21 items); and design consistency (nine items). As mentioned previously, each of these seven concepts is highlighted in the literature as a cue consumers use to judge the authenticity of an object or brand. Our objective in generating scale items was to ensure that we captured the essence of what authenticity means to consumers, which resulted in a broad pool of items reflecting these seven concepts. Content validity of the initial pool of items was then assessed. Following the method outlined by Bearden, Netemeyer and Teel (1989), five marketing academics were provided with a definition of brand authenticity and each the seven dimensions coupled with an example scale item. The judges were then asked to assign each of the 157 items to one of the dimensions or to 'none of these' categories. Items that did not receive consistent classification by at least four of the five judges were eliminated. This resulted in 90 items being eliminated reducing the item pool to 67 items.

Next, an expert sample consisting of four more marketing academics (different from the above respondents) judged the remaining items (Bearden et al., 1989; Zaichkowsky, 1985). Each judge was provided with a definition of brand authenticity and each of its dimensions and a list of items purported to measure each dimension. The judges were then asked to rate each statement as being 'not at all representative', 'somewhat representative' or 'clearly representative' of the stated dimension. Items that were evaluated as 'clearly representative' by at least three of the four judges but not worse than 'somewhat representative' by the fourth judge were retained. This process resulted in a further 34 items being eliminated. The final sample of scale items consisted of 33 items. 
Items were placed on a seven-point Likert scale, anchored by 1 'strongly disagree' and 7 'strongly agree,' and pilot tested among 40 undergraduate students. Respondents were asked to think of a brand they considered to be truly authentic and record how strongly they felt each item reflected their nominated brand. The only changes made were with respect to the instructions given to respondents for completing the survey. All items were otherwise retained for further analysis.

\subsection{Study 2 - Item Reduction and Reliability Testing}

The second stage of the research involved further purification of scale items and an assessment of the internal reliability of the 33 items. Data was collected via a self-administered questionnaire using undergraduate students at a large inner city university. Students are considered to be relevant surrogates for adult consumers when the research is designed to measure attitudes rather than behaviors (Beltramini, 1983; Khera \& Benson, 1970) and for testing multivariate relationships among constructs rather than differences between groups (Calder, Phillips, \& Tybout, 1981).

Each of the 33 scale items were placed on a seven-point scale anchored by 1 'strongly disagree' and 7 'strongly agree'. Respondents were again asked to think of a brand they considered to be truly authentic and record how strongly they felt each item reflected their nominated brand. Data was collected from 252 university students. Of these, five questionnaires could not be used due to incomplete responses. The final sample consisted of 247 respondents. The average age was 23 years, with a relatively even split between male $(43 \%)$ and female $(57 \%)$ respondents.

The first stage of scale purification involved the 33 brand authenticity items undergoing the computation of Cronbach alpha. Items with a corrected item-to-total correlation of less than .4 were eliminated, resulting in the deletion of four items. The remaining scale items were then subjected to a principal components analysis with an oblique rotation. The Kaiser-Meyer Olkin 
$(\mathrm{KMO})$ value of .918 and a significant chi-square value for the Bartlett test for sphericity $\left(\mathrm{X}^{2}=\right.$ 2480.66, $\mathrm{p}<.001)$ indicated that factor analysis was appropriate for the data. Factor extraction according to the MINEIGEN criterion (ie. all factors with Eigenvalues $>1$ ) was employed. Ten items failed to exhibit a simple factor structure on any one factor and were subsequently deleted. The final set of 19 items reflected a three factor solution, accounting for $60 \%$ of the variance. The Cronbach alpha for the 19-item scale was $.922(\mathrm{n}=247)$, which is within Nunnally’s (1978) guidelines for scale development.

The first factor corresponded with the quality commitment dimension of brand authenticity (nine items, $\alpha=.926$ ), the second captured the heritage dimension (six items, $\alpha$ $=.817$ ) and the third represented the sincerity dimension (four items, $\alpha=.744$ ). The Cronbach alphas for each of the dimensions fall within Nunnally's (1978) guidelines and attest to the internal consistency of the scale. The correlations between these dimensions were all positive and significant (Quality commitment--Heritage, r=.546; Quality commitment--Sincerity, $\mathrm{r}=.595$; Heritage--Sincerity, $\mathrm{r}=.506$ ). These items formed the basis for further structural testing through confirmatory factor analysis in study 3.

\subsection{Study 3 - Confirmatory Factor Analysis}

In order to evaluate the remaining brand authenticity items and the underlying factor structure, a series of confirmatory factor models were examined using data gathered from a second sample of 203 university students. Respondents were asked to think of a brand they considered to be somewhat authentic and record how strongly they felt each of the 19 items reflected their nominated brand (items were placed on a seven-point scale anchored by 1 'strongly disagree' and 7 'strongly agree'). 
Using data obtained from the second sample, structural equation modeling was used to perform a confirmatory factor analysis. Several alternative models were examined including: the null model, a one factor model for which all of the remaining items were forced to load on a single factor, several two factor models, a three factor uncorrelated model and a three factor correlated model. Initial examination of the modification indices and standardized residual covariances suggested the deletion of five additional items (B2 'The brand reinforces and builds on long-held traditions'; B3 'The brand remains true to its espoused values', B4 'The brand has a mark of distinction that signifies quality'; B25 'The brand builds on traditions that began with its founder'; and B33 'It feels like artisan skills and customized manufacturing processes have been retained in the production of this brand'). These revisions resulted in 14 items representing three factors as follows: quality commitment (seven items), sincerity (two items) and heritage (five items).

While nostalgia, craftsmanship and design consistency did not emerge as separate factors these concepts are nonetheless represented by the 14 remaining items. Nostalgia and design consistency form part of the heritage dimension and are represented by items B1 ("The brand reminds me of a golden age"), B7 ("The brand has a strong link to the past, which is still perpetuated and celebrated to this day") and B10 ("The brand reflects a timeless design"), while craftsmanship is part of quality commitment (represented by items B5 "The brand is made by a master craftsman who pays attention to detail and is involved throughout the production process" and B31 "Only the finest ingredients/materials are used in the manufacture of this brand"). Cultural symbolism did not emerge as a separate component of brand authenticity nor is it represented by one of the other dimensions. In the context of this study cultural symbolism represents the meaning a brand acquires as it becomes synonymous with certain cultural values evident in society. Such brands may become icons. Given that all of the items representing this dimension were deleted in the analysis it raises the question of whether cultural symbolism is a driver of brand authenticity. Our findings suggest that it is not 
and the reason for this may be that although a brand becomes synonymous with certain cultural values, consumers may not regard it as authentic because those values are either undesirable, unimportant or lack special meaning among brand users. Perhaps the inclusion of cultural symbolism as a brand authenticity cue in the first stage of this project was misdirected. Future research could certainly examine the relationship between cultural symbolism and brand authenticity in more depth and this may lend further insight into its relevance as a driver of brand authenticity.

As shown in Table 2, the three factor correlated model provided the best fit of the data. The fit statistics were chi-square $=100.84,74$ degrees of freedom $(\mathrm{p}=.021)$; comparative fit index $(\mathrm{CFI})=.976$, Non-normed fit index $(\mathrm{TLI})=.971$, Normed Fit Index $(\mathrm{NFI})=.917$, and the root mean square error of approximation $($ RMSEA $)=.042$, which are within the guidelines recommended by Kelloway (1998). The results of the confirmatory factor analysis indicate that Quality Commitment, Sincerity and Heritage are three first-order factors that correspond with a higher order brand authenticity construct.

\section{Insert Table 2 in here}

Cronbach alphas for the three factors of brand authenticity based on the study 3 data are as follows: quality commitment $(\alpha=.879)$, heritage $(\alpha=.783)$ and sincerity $(\alpha=.605)$. Further, the Spearman-Brown coefficient for the sincerity dimension was .637, which is considered a robust indicator of the reliability of two-item constructs (Bollen 1989; Eisinga, Grotenhuis and Pelzer 2012). These results are similar to the estimates obtained for study 2 . The corresponding composite reliability estimates for the three factor correlated model, based on the sum of the standardized loadings squared divided by the sum of the loadings squared added to the sum of the item variance (Fornell \& Larcker, 1981), are shown and Table 3 and further attest to the internal consistency of the scale. Based on Fornell and Larcker's (1981) test for convergent 
validity, whereby the average variance extracted for each construct should be greater than .5 , the values for both the sincerity and heritage dimension fall marginally below this criteria. Further evidence was therefore required before confirming convergent validity of the BA scale. Discriminant validity is evident when the average variance extracted for each construct is greater than the squared correlation between that construct and any other construct in the model (Fornell \& Larcker, 1981). As shown in Table 3, discriminant validity of the scale is supported.

Insert Table 3 in here

To further assess the construct and predictive validity of the scale, data were collected from a third group of respondents comprised of consumers rather than students. Results from Study 4 are discussed below.

\subsection{Study 4 - Assessing Construct and Predictive Validity}

The purpose of this study was to evaluate the construct and predictive validity of the BA scale. Construct validity studies check the theory underlying the test (French \& Michael, 1966). This involves first, establishing propositions about the attitudes of consumers scoring high and low on the brand authenticity construct, second, collecting data to determine if the scale discriminates on attitudes and third, inferring whether the theory is adequate in explaining the data collected (Zaichkowsky, 1985). To do so, the survey used in Study 4 included measures for two conceptually related yet distinct constructs, namely brand trust (adapted from DelgadoBallester, 2004) and brand credibility (adapted from Kirmani, 1997).

Brand trust is conceptualized as "the confident expectations of the brand's reliability and intentions in situations entailing risk to the consumer" (Delgado-Ballester 2004, p. 574). Consumers tend to trust a brand if they feel a brand will perform as expected or promised, and 
if an unexpected problem does arise, a belief that the firm will endeavor to resolve the issue. Consumers may focus on the more tangible features of a product and its performance to make such evaluations. However, with the modern-day market place characterized by a higher level of consumer cynicism (Arnould \& Price, 2000; Firat \& Venkatesh, 1995), it is becoming increasingly difficult to build brand trust, particularly as brands are so commonly associated with deception, trickery and exaggeration (Holt 2002). Authentic brands, however, are the antithesis of this - consumers have faith that a firm's actions are driven by love for the product, not profits, and they will act in the best interests of its customers and society (Beverland, 2005). Unlike brand trust, the cues consumers use to form beliefs about a brand's authenticity may not always be tangible, real or even true (Costa \& Bamossy, 2001; Grayson \& Martinec, 2004; Rose \& Wood, 2005), yet authentic brands seem to be trusted nonetheless. Delivering an authentic brand experience, then, is imperative to building brand trust and achieving firm growth in the long term (Eggers et.al. 2012).

Brand authenticity can also be distinguished from brand credibility. Brand credibility relates to the trustworthiness, reliability and believability of an entity's intention at a particular point in time (Herbig \& Milewicz, 1993). An individual who rates a brand as being authentic may also believe it to be credible (ie. reliable, trustworthy, believable). Yet a brand that is perceived as credible may not be regarded as authentic because it may have a strong commercial orientation or be lacking in tradition or passion to craft, for example. Such factors contribute to a consumer's personal and often subjective construction of authenticity but not credibility. While we expect that a correlation would exist between measures of brand authenticity and that of brand trust and brand credibility, they are conceptually distinct constructs and therefore should also be empirically distinct.

The final measure included in the survey was that of purchase intention, which was used to assess the predictive validity of the scale. As noted earlier, consumers' authenticity evaluations are subjective, personally constructed and changeable over time (Grayson \& 
Martinec, 2004; Peterson, 1997), reflecting a consumer's attitudes and beliefs toward an object. Prior research has consistently demonstrated a positive association between an individual's attitude toward an object or situation and their subsequent behavior (Ajzen \& Fishbein, 1980; Bagozzi, Baumgartner, \& Yi, 1989; Bearden \& Woodside, 1977; Fishbein \& Ajzen, 1975). Thus, if a consumer has a positive attitude toward a brand then they are more likely to purchase that brand. In studies examining such issues, purchase intention has often been used as a proxy or indicator of actual purchase behavior. From this perspective, if authenticity evaluations are seen as an aspect of attitude and attitude predicts purchase intention, we expect to observe a positive association between brand authenticity evaluations and purchase intention, which will confirm the predictive validity of the BA scale. Purchase intention was measured by three items (adapted from Putrevu \& Lord, 1994) and measured on a 7-point scale anchored by 1 'strongly disagree' and 7 'strongly agree' (see Appendix A).

\subsubsection{Method}

To assess the construct and predictive validity of the BA scale, a third survey was administered to adult consumers. Data was collected from adult consumers electronically through an organization that specializes in administering surveys online. The database is comprised of consumers who have registered an interest in participating in online research programs. The organization recruits panel members 'offline' through national free to air TV, paid channels, magazines and radio. Consumers who choose to participate in a study receive a reward from the organization in the form of points, which can be used toward the redemption of products. Responses were received from 312 consumers. Of these, 206 respondents were asked to report on a brand they considered to be authentic (Sample A), while the remainder (106 respondents) were required to report on a brand they considered inauthentic (Sample B). The median age of respondents in both samples was 31 and 29 years, respectively. 


\subsubsection{Results - Construct Validity}

Using data from Sample A ( $\mathrm{n}=206)$, subjects were classified into two groups based on their overall evaluations of the authenticity of the brand (ie. high versus low authenticity evaluations). In so doing, we addressed the question of whether respondents with a low BA score would report low ratings for brand trust and brand credibility, relative to those with a high BA score. Comparison between the two groups was carried out through an independent samples t-test. In addition, the Pearson correlation between the overall BA scale score and the responses to each of the two other constructs were also computed (Zaichkowsky, 1985). Results are reported in Table 4 and as can be seen, significant differences between the two groups along the dimensions of brand trust and brand credibility are observed along with positive significant correlations across these variables. Thus, the higher the authenticity rating for a brand the more likely it is a brand will be perceived as being reliable and acting with the right intentions (ie. trusted) and have more credibility in the market place. The above analysis was then repeated using data collected from Sample B (ie. respondents were asked to report on an inauthentic brand), which revealed a similar pattern (see Table 4). That is, the more inauthentic a brand is perceived, the less trusted it is and the less credibility it appears to have in the minds of consumers. Combined, these results suggest that the proposed BA scale does tap the construct of authenticity and so is an acceptable measure of authenticity.

From a theoretical perspective brand authenticity is conceptually similar yet distinct from brand trust and credibility. The high positive correlations between each of these constructs, however, may suggest a lack of discriminant validity between factors. This was tested by examining whether for every pair of factors, the fit for a two-factor model was significantly better than a one-factor model (Gerbing \& Anderson, 1988). In all cases, a two factor model 
did fit significantly better than a one-factor model leading us to conclude that the BA measure is clearly discriminated from the other scales examined in this study. Results are shown in Table 5. Finally, the average variance extracted for each of the dimensions of quality commitment, heritage and sincerity were $.659, .541$ and .524 , respectively, which exceed Fornell and Larcker's (1981) recommendation and thus point to the convergent validity of the BA scale.

\section{Insert Table 5 in here}

\subsubsection{Results - Predictive Validity}

The final test employed in this study was to assess whether positive brand authenticity evaluations are a significant predictor of purchase intention. Three brand authenticity dimensions were formed by summating the scores for the individual items comprising each factor and then regressed onto the purchase intention measure. The adjusted $R^{2}$ of .499 $(\mathrm{p}<.001)$ suggests that a significant proportion of the variation in a consumer's intention to purchase a brand is accounted for by the components of BA, with all three factors being significant predictors of purchase intention (quality commitment, $\beta=.646(p<.001)$, sincerity, $\beta=.162(p<.05)$ and heritage, $\beta=.112(p<.1))$. Predictive validity of the BA scale was further assessed through structural equation modeling, whereby the three interrelated first-order factors of quality commitment, heritage and sincerity load onto a global BA variable which then predicts purchase intention. The fit statistics were chi-square $=259.92,87$ degrees of freedom $(\mathrm{p}<.001)$; comparative fit index $(\mathrm{CFI})=.917$, non-normed fit index $(\mathrm{TLI})=.899$, normed fit index $(\mathrm{NFI})=.881$, and the root mean square error of approximation $(\mathrm{RMSEA})=.098$, which were close to Kelloway's (1998) recommended values. Results suggest that brand authenticity evaluations are a significant predictor of purchase intentions $(\gamma=.697, p<.001)$. 
Overall, the results from Study 4 support the stability of the CBBA scale, with quality commitment, sincerity and heritage being three first-order factors reflecting a higher order brand authenticity construct. Further, brand authenticity is empirically discriminated from brand trust and credibility and is a significant predictor of purchase intentions.

\section{DISCUSSION}

Authenticity is increasingly cherished as its existence in the commercial world gradually diminishes (Penaloza 2000; Peterson 2005). People today are discontented with this commercial existence and lack faith in marketing, with almost everything in their lives seeming to be contrived. Therefore consumers are ready to embrace alternate consumption behaviors. While this shift is a movement concentrated among a few consumer sub groups, and the revolution in consumption predicted by Boyle (2003) may be some time away, the consumers' quest for authenticity will drive marketers to reassess their strategies. Penaloza (2000) notes that this search for authenticity is not a fad, but a real consumer attempt to change the social order surrounding consumption and marketing. Consumers feel they have been denied an existence that is real or authentic and are going to demand products that reflect the renewed desire for what is authentic. Thus, it is important that authenticity claims capture the experiences, expectations and desires of the proposed target and reflect their prevailing values and beliefs (Molleda, 2010).

In this study we broaden our understanding of brand authenticity as a multidimensional construct by developing a psychometrically robust measure of brand authenticity. A series of four studies, integrating a range of methodologies, suggest that brand authenticity is both a theoretically and managerially relevant construct, and that the scale has acceptable reliability and validity. All four studies make use of known psychometric procedures and standards similar to those reported in other scale development efforts (eg. Thomson, MacInnis, \& Park, 2005; Voss, Spangenberg, \& Grohmann, 2003). Findings demonstrate convergent, discriminant 
and predictive validity, whereby 14 items represent three interrelated first order factors labeled quality commitment, sincerity and heritage that correspond with a higher order brand authenticity construct. This result is consistent across multiple studies and samples.

These three dimensions of the CBBA scale share some commonality with the components identified in the Authentic Brand Index, which help establish the power of a brand in the mind of consumers. That is, they are the drivers that are reflective of a brand's ability to create enduring mental associations between the brand and things that matter to an individual, which is the core of authenticity (authenticbrandindex.com). Eggers et.al. (2012) define brand authenticity in terms of brand consistency and brand congruency and suggest that it is important for firms to have clearly defined values that reflect where they have come from and who they are today and importantly, being consistent in their actions to reflect these values and core beliefs. Conversely the CBBA scale stresses similar concepts, that is firms must act sincerely, be committed to providing enduring high quality products and services that are reflective of a brand's heritage, without deviating substantially from the core attributes on which the brand was initially built. It seems then, that our findings and those of Eggers et.al. (2012), represent two sides of the same coin - that is, CEOs and consumers tend to define brand authenticity in a similar manner. This suggests that quality commitment, heritage and sincerity are important drivers of brand authenticity, both from an organizational and consumer perspective.

The scale can be used to examine how consumers determine brand authenticity and expedite strategy decisions regarding a firm's delivery of authenticity. Research needs to explore the benefits that consumers experience when they consume or experience something authentic (Grayson \& Martinec, 2004) as well as considering marketing implications, and specifically, the use of brand authenticity as a positioning device. Positioning a brand based on product superiority, quality and great service are all too common in the competitive market, whereas authenticity allows a brand to be true without being perfect (Beverland, 2005; 
Beverland et al., 2008), and is well fitted with current social movements (Brown et al., 2003; Moore 2006). However, simply claiming to be authentic is not going to make a firm successful in terms of this positioning - authenticity needs to be demonstrated as central to the brand (Beverland, 2005; Gilmore and Pine, 2007).

While consumers are looking for added value in brands such as a story, spirituality or a sense of community it would be improper to suggest that the creation of authenticity is the sole means to deliver this added value. By being able to measure and assess authenticity, however, marketers may be empowered to identify new opportunities for brand positioning and value creation that may contribute to greater consumer loyalty and attachment to the brand. Developing greater authenticity potentially enables firms to be more effective in satisfying human needs (Moore 2006), whilst improving the effectiveness of strategic communications, corporate performance and behavior (Molleda, 2010).

With this scale, brand authenticity can also be tracked over time, allowing managers to determine a brand's strengths and weaknesses relative to competing brands, and the drivers of and impediments to achieving an authentic brand positioning. Such knowledge can inform the direction of future advertising and communications strategies, allowing managers to put in place programs that either reinforce or change consumer brand perceptions. In addition, it can assist managers in making decisions about future brand extensions, sponsorship choices and cobranding partnerships by providing a means by which to evaluate the authenticity of their own brand and that of prospective partners, ensuring proper brand fit is maintained.

\section{LIMITATIONS AND RESEARH DIRECTIONS}

There are several limitations to be noted. First, although a review of the literature highlighted seven potential cues consumers use in evaluating the authenticity of a brand, only three factors emerged in our analysis, namely quality commitment, heritage and sincerity. The concepts of nostalgia, craftsmanship and design consistency were captured by these three factors, but 
cultural symbolism failed to materialize in any form. This suggests that the CBBA scale does embrace the core elements of brand authenticity as highlighted in the literature, and findings are consistent with Eggers et.al. (2012) and the Authentic Brand Index (authenticbrandindex.com). Yet some question remains as to whether cultural symbolism should form part of this scale. Perhaps the way in which the construct was initially conceptualized and operationalized was incorrect. This represents a limitation of this study but also opens further avenues for future research.

Second, in this study sincerity is measured by two items, which are related to a brand's values (item B6 "The brand refuses to compromise the values upon which it was founded") and principles (item B30 "The brand has stuck to its principles"). Interestingly, specific items related to consumers' perceptions of a brand's commercial motives did not emerge during analysis. This suggests that sincerity, when examined in the context of brand authenticity, relates to values and principles. However, in a broader context, sincerity may be a more complex construct that involves a wider range of issues beyond those identified here. This is potentially a limitation of the study, on which additional research could shed more light.

Third, while we have used the classical test of discriminant validity for the CBBA scale and have followed the procedure outline by Fornell and Larcker, (1981), measures for each of the constructs in question have been obtained from the same source (or rater), which may have an effect on the results produced (Podsakoff, MacKenzie, Lee and Podsakoff 2003). We attempted to minimize common method bias by protecting respondent anonymity, reducing evaluation apprehension and ensuring all scale items were clear an unambiguous (Podsakoff et.al. 2003), but it is nonetheless, a limitation of this study. Future research could be directed at using a Multitrait-Multimethod (MTMM) model (Campbell and Fiske 1959) to control for method variance and confirm discriminant validity of the CBBA scale. By collecting data using different measures and different methods, any problems with discriminant validity will become evident. However, this is cumbersome, requires more data collection and given the 
judgmental nature of MTMM models, may suffer from interpretation issues, with different researchers legitimately arriving at different conclusions (Bollen 1989).

In this study, respondents were asked to nominate any brand they considered to be authentic, irrespective of product category. Determining variations in authenticity evaluations across levels of involvement, levels of branding (i.e. corporate versus product) and types of goods (i.e. symbolic, experiential and utilitarian goods), would be of interest (Aaker, 1997; Yoo \& Donthu, 2001) as this may lend insight into the specific category or type of brand for which an authentic positioning is desirable. Further research may also focus on the nature of brand authenticity as it also relates to services, given that the human aspect of service delivery may elicit a different factor structure for brand authenticity to that which emerged in this study. Do consumers use different cues to evaluate the authenticity of a service brand versus a product brand and if so, what are the critical drivers? Brand authenticity evaluations may also vary across cultures so it would be relevant to examine the aspects and dimensions that are shared amongst different cultural groups (and even market segments) as this has implications for managing brands across cultures. Such research may act to confirm the structure of brand authenticity and extend the generalizability of the scale. Research could seek to examine the relationships between a brand's authenticity and its equity as measured by published databases (ie., Interbrand or Millward Brown), identifying the impact (if any) on brand equity of changes in overall authenticity or any of its three components. Finally, future research using conjoint analysis would also be useful to determine how consumers value the different aspects of brand authenticity and therefore those elements that are most influential in the assessment of a brand being perceived as authentic. 


\section{APPENDIX A \\ Constructs and Items used to Assess Construct and Predictive Validity}

\section{Brand Trust (Delgado-Ballester, 2004),}

Brand Reliability $(\alpha=.937)$ :

- The brand meets my expectations

- I feel confidence in the brand

- The brand never disappoints me

- The brand name guarantees satisfaction

Brand Intentions $(\alpha=.826)$ :

- The brand would be honest and sincere in addressing my concerns

- I could rely on the brand to solve the problem

- The brand would make any effort to satisfy me

- The brand would compensate me in some way for the problem with the product

\section{Brand Credibility (adapted from Kirmani, 1997) $(\alpha=.758)$}

- I think the brand is trustworthy

- I think the brand is competent

- I think the brand is honest

- *I have very little confidence in the quality of the brand

Purchase Intention (Putrevu \& Lord, 1994) $(\alpha=.926)$

- It is very likely that I will buy this brand

- I will purchase this brand the next time I need this type of product

- I will definitely try this brand

Items measured on a 7-point scale, anchored by 1 'strongly disagree' and 7 'strongly agree.

*Reverse coded; 
Table 1 Factor Analysis

KMO and Bartlett's Test

\begin{tabular}{|c|c|c|}
\hline \multicolumn{2}{|c|}{ Kaiser-Meyer Olkin Measure of Sampling Adequacy } & .918 \\
\hline Bartlett's Test of Sphericity & $\begin{array}{l}\text { Approx. Chi-Square } \\
\text { df. } \\
\text { Sig. }\end{array}$ & $\begin{array}{l}2480.66 \\
171 \\
.000\end{array}$ \\
\hline & Communalities & \\
\hline Item & Extraction & \\
\hline B1 & .500 & \\
\hline $\mathrm{B} 2$ & .591 & \\
\hline B3 & .586 & \\
\hline B4 & .601 & \\
\hline B5 & .611 & \\
\hline B6 & .569 & \\
\hline B7 & .602 & \\
\hline $\mathrm{B} 10$ & .439 & \\
\hline B11 & .638 & \\
\hline B14 & 691 & \\
\hline B16 & .742 & \\
\hline $\mathrm{B} 18$ & .654 & \\
\hline B21 & .707 & \\
\hline $\mathrm{B} 25$ & .482 & \\
\hline B27 & .570 & \\
\hline $\mathrm{B} 29$ & .564 & \\
\hline B30 & .565 & \\
\hline B31 & .665 & \\
\hline B33 & .556 & \\
\hline
\end{tabular}

Total Variance Explained

\begin{tabular}{|c|c|c|c|c|c|c|c|}
\hline \multirow[t]{2}{*}{ Component } & \multicolumn{3}{|c|}{ Initial Eigenvalues } & \multicolumn{3}{|c|}{$\begin{array}{l}\text { Extraction Sums of Squared } \\
\text { Loadings }\end{array}$} & \multirow{2}{*}{$\begin{array}{l}\text { Rotation } \\
\text { Total }\end{array}$} \\
\hline & $\begin{array}{l}\text { Tota } \\
\text { l }\end{array}$ & $\begin{array}{l}\text { \% of } \\
\text { Var. }\end{array}$ & $\begin{array}{l}\text { Cum. } \\
\%\end{array}$ & Total & $\%$ of Var. & $\begin{array}{l}\text { Cum. } \\
\%\end{array}$ & \\
\hline $\begin{array}{l}\text { Quality } \\
\text { commitment }\end{array}$ & 8.15 & 42.89 & 42.89 & 8.15 & 42.89 & 42.89 & 7.14 \\
\hline Heritage & 1.88 & 9.94 & 52.83 & 1.89 & 9.94 & 52.83 & 4.89 \\
\hline Sincerity & 1.29 & 6.80 & 59.64 & 1.29 & 6.80 & 59.64 & 4.61 \\
\hline
\end{tabular}

Pattern Matrix

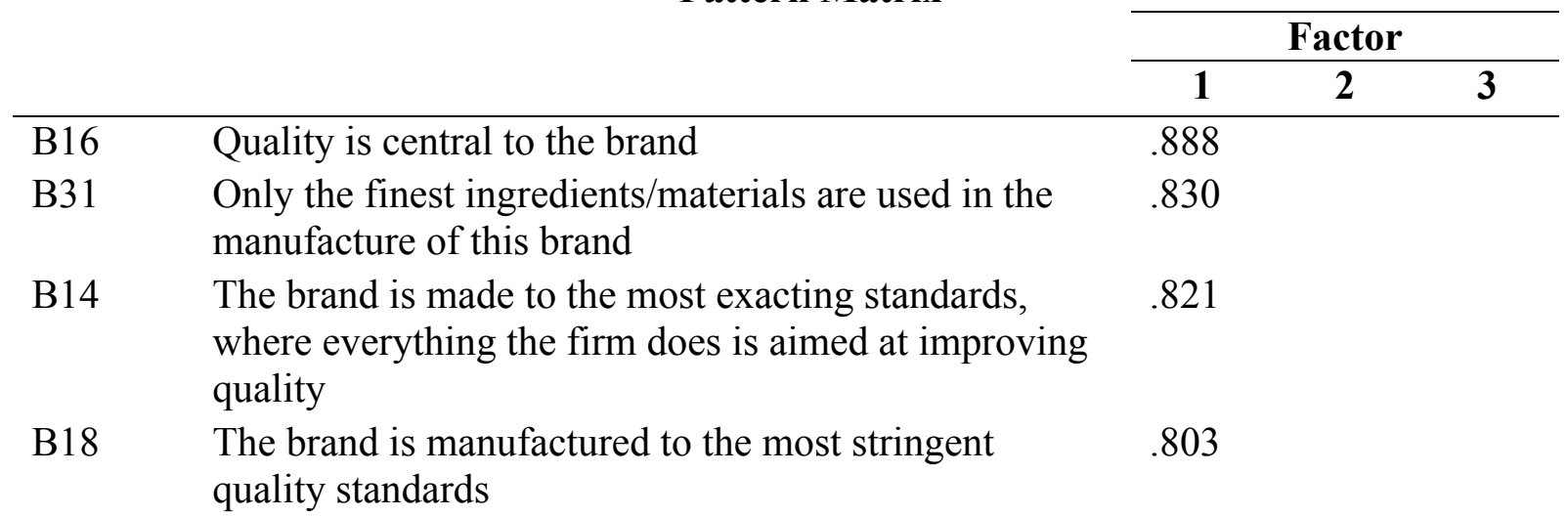


B33 It feels like artisan skills and customized

manufacturing processes have been retained in the

production of this brand

B21 The brand is a potent symbol of continued quality

$\begin{array}{ll}\text { B5 The brand is made by a master craftsman who pays } & .718\end{array}$ attention to detail and is involved throughout the production process

B11 The firm is committed to retaining long-held quality $\quad .609$ standards for the brand

B4 The brand has a mark of distinction that signifies quality

B27 The brand has a strong connection to an historical period in time, culture and/or specific region

B7 The brand has a strong link to the past, which is still perpetuated and celebrated to this day

B1 The brand reminds me of a golden age

B29 The brand exudes a sense of tradition

B2 The brand reinforces and builds on long-held traditions $\quad .656$

B10 The brand reflects a timeless design

B3 The brand remains true to its espoused values which it was founded

B30 The brand has stuck to its principles

B25 The brand builds on traditions that began with its founder 
Table 2

Confirmatory Factor Analysis Model Fit Comparison

\begin{tabular}{lllllllll}
\hline Model & Chi- & Df & p- & Chi-square & CFI & TLI & NFI & RMSEA \\
& square & & value & difference & & & & \\
& & & & & & & & \\
\hline Null & 1218.15 & 91 & & $\ldots$ & NA & NA & NA & NA \\
1-factor & 320.87 & 77 & .000 & $897.28^{* *}$ & .784 & .744 & .737 & .125 \\
2-factor correlated & 302.43 & 77 & .000 & $18.44^{* *}$ & .800 & .764 & .752 & .132 \\
(QC\&H combined) & & & & & & & & \\
3-factor uncorrelated & 194.82 & 78 & .000 & $107.61^{* *}$ & .896 & .879 & .840 & .086 \\
2-factor correlated & 145.15 & 76 & .000 & $49.67^{* *}$ & .939 & .927 & .881 & .067 \\
(H\&S combined) & & & & & & & & \\
2-factor correlated & 131.97 & 76 & .000 & $13.18^{* *}$ & .950 & .941 & .892 & .060 \\
(QC\&S combined) & & & & & & & & \\
3-factor correlated & 100.84 & 74 & .021 & $31.13^{* *}$ & .976 & .971 & .917 & .042 \\
\hline
\end{tabular}

Note: $\mathrm{df}$ is degrees of freedom, CFI is Comparative Fit Index, TLI is Non-Normed Fit Index, NFI is Normed Fit Index and RMSEA is Root Mean Square Error of Approximation

${ }^{\mathrm{a}}$ Chi-square differences represent comparisons of subsequent models (e.g., null vs. 2-factor uncorrelated, (QC\&H combined), 2-factor uncorrelated (QC\&H combined) vs 1-factor, etc.) $* * \mathrm{p}<.01$ 
Table 3

Reliability and Validity Assessment for BA scale

\begin{tabular}{lccccc}
\hline \multicolumn{2}{l}{ Quality Commitment } & Heritage & \multicolumn{3}{c}{ Sincerity } \\
\hline CR & AVE & CR & AVE & CR & AVE \\
.892 & .546 & .792 & .442 & .608 & .437 \\
\hline
\end{tabular}

\begin{tabular}{llll}
\hline Quality Commitment- & Quality Commitment- & Sincerity- & DV \\
Heritage & Sincerity & Heritage & \\
\hline .217 & .376 & .287 & Yes \\
\hline
\end{tabular}

$\mathrm{CR}=$ Composite Reliability $=\left(\sum \text { of Std.Loadings }\right)^{2} /\left(\sum \text { of Std.Loadings }\right)^{2}+\sum$ of $\varepsilon_{\mathrm{j}}$

$\mathrm{AVE}=$ Average Variance Extracted $=\sum$ of $(\text { Std.Loadings })^{2} / \sum$ of $(\text { Std.Loadings })^{2}+\sum$ of $\varepsilon_{\mathrm{j}}$

$\mathrm{DV}=$ Discriminant Validity $=\mathrm{AVE}>(\mathrm{Corr})^{2}$; 


\section{Table 4}

Relationship between construct validity measures and high versus low Authentic (Sample A) and Inauthentic (Sample B) scores: Means, stand deviations and correlations

\begin{tabular}{|c|c|c|c|c|c|c|}
\hline \multirow{2}{*}{$\begin{array}{l}\text { Construct Validity } \\
\text { Dimensions }^{\mathrm{a}}\end{array}$} & \multicolumn{3}{|c|}{ Sample A: Authentic Brands } & \multicolumn{3}{|c|}{ Sample B: Inauthentic Brands } \\
\hline & $\begin{array}{l}\text { Low } \\
(n=99)\end{array}$ & $\begin{array}{l}\text { High } \\
(n=107)\end{array}$ & $\mathbf{r}^{\mathbf{b}}$ & $\begin{array}{l}\text { Low } \\
(n=56)\end{array}$ & $\begin{array}{l}\text { High } \\
(\mathrm{n}=\mathbf{5 0})\end{array}$ & $\mathbf{r}^{\mathbf{b}}$ \\
\hline \multicolumn{7}{|l|}{ Brand Trust: } \\
\hline Reliability (4 items) & $\begin{array}{l}19.18 * \\
(4.88)\end{array}$ & $\begin{array}{l}26.04 \\
(2.33)\end{array}$ & $.788^{\mathrm{c}}$ & $\begin{array}{l}10.32 \\
(4.09)\end{array}$ & $\begin{array}{l}5.30 * \\
(1.79)\end{array}$ & $.688^{\mathrm{c}}$ \\
\hline Intention (4 items) & $\begin{array}{l}18.09 * \\
(3.81)\end{array}$ & $\begin{array}{l}24.12 \\
(3.35)\end{array}$ & $.788^{c}$ & $\begin{array}{l}11.09 \\
(3.81)\end{array}$ & $\begin{array}{l}5.66 * \\
(2.99)\end{array}$ & $.695^{\mathrm{c}}$ \\
\hline Brand Credibility (4 items) & $\begin{array}{l}19.73 * \\
(4.61)\end{array}$ & $\begin{array}{l}25.03 \\
(2.83)\end{array}$ & $.636^{\mathrm{c}}$ & $\begin{array}{l}11.48 \\
(4.02)\end{array}$ & $\begin{array}{l}8.00 * \\
(3.05)\end{array}$ & $.523^{\mathrm{c}}$ \\
\hline
\end{tabular}

\footnotetext{
${ }^{a}$ Summated scales measured on a seven point scale: (1) Strongly disagree to (7) strongly agree

${ }^{\mathrm{b}} \mathrm{r}=$ Pearson correlation between BA scores and responses to construct validity dimensions

${ }^{\mathrm{c}} \mathrm{p}<.001$

* Low scores significantly different from high scores at $\mathrm{p}<.001$
} 
Table 5

Confirmatory Factor Analysis Model Fit Comparison (n=206)

\begin{tabular}{|c|c|c|c|c|c|c|c|c|}
\hline Model & $\begin{array}{l}\text { Chi- } \\
\text { square }\end{array}$ & Df & $\begin{array}{l}\text { p- } \\
\text { value }\end{array}$ & $\begin{array}{l}\text { Chi-square } \\
\text { difference }^{\mathrm{a}}\end{array}$ & CFI & TLI & NFI & RMSEA \\
\hline \multicolumn{9}{|l|}{ BA - Brand Trust } \\
\hline Null & 860.807 & 10 & & $\ldots$ & NA & NA & NA & NA \\
\hline 1-factor & 35.318 & 5 & .000 & $825.489 * *$ & .964 & .929 & .959 & .172 \\
\hline 2-factor correlated & 27.634 & 4 & .000 & $7.684 * *$ & .972 & .931 & .968 & .170 \\
\hline \multicolumn{9}{|c|}{ BA-Brand Credibility } \\
\hline Null & 1078.616 & 21 & & $\ldots$ & NA & NA & NA & NA \\
\hline 1-factor & 106.658 & 14 & .000 & $971.958 * *$ & .912 & .869 & .901 & .180 \\
\hline 2-factor correlated & 56.473 & 13 & .000 & $50.185^{* *}$ & .959 & .934 & .948 & .128 \\
\hline
\end{tabular}

Note: $\mathrm{df}$ is degrees of freedom, CFI is Comparative Fit Index, TLI is Non-Normed Fit Index, NFI is Normed Fit Index and RMSEA is Root Mean Square Error of Approximation

${ }^{a}$ Chi-square differences represent comparisons of subsequent models (e.g., null vs. 2-factor (QH-S) uncorrelated, 2-factor (QH-S) uncorrelated vs 1-factor, etc.)

$* * \mathrm{p}<.01$ 


\section{ACKNOWLEDGEMENTS}

The authors would like to thank Peter Danaher, Tim Fry and Mike Reid for their helpful comments on earlier drafts. We would also like to thank Leyland Pitt, Pierre Berthon, Ian Phau, Donna Gill, Rod Brodie, Tandy Chellis and Nicole Porter for their assistance in the scale refinement process. Thanks also to the Faculty Research Committee at the University of Melbourne for funding this project. 


\section{REFERENCES}

Aaker, D.A. (1997). Dimensions of brand personality. Journal of Marketing Research, 34(3), 347-356.

Ajzen, I. \& Fishbein, M. (1980). Understanding attitudes and predicting social behavior. London: Prentice Hall.

Alexander, N. (2009). Brand authentication: creating and maintaining brand auras. European Journal of Marketing, 43(3/4): 551-562.

Arnould, E.J. \& Price, L.L. (2000). Authenticating acts and authoritative performances: Questing for self and community. In S. Ratneswar, D. G. Mick, \& C. Huffman (Eds.), The Why of Consumption: Contemporary Perspectives on Consumer Motives (pp. 140-163). New York: Routledge.

Authentic brand index - A study of the most authentic brands in Australia (2008), (available via: authenticbrandindex.com)

Bagozzi, R. P., Baumgartner, J. \& Yi, Y. (1989). An investigation into the role of intentions as mediators of the attitude-behavior relationship. Journal of Economic Psychology, 10(1), $35-62$.

Bearden, W.O., Netemeyer, R.G. \& Teel, J.E. (1989). Measurement of consumer susceptibility to interpersonal influence. Journal of Consumer Research, 15(4), 473-481.

Bearden, W.O. \& Woodside, A.G. (1977). Testing variations of Fishbein's behavioral intention model within a consumer behavior context. Journal of Applied Psychology, 62(3), 352-357.

Belk, R.W. (1988). Possessions and the extended self. Journal of Consumer Research, 15(2), 139-168.

Belk, R.W. \& Costa, J.A. (1998). The mountain man myth: A contemporary consuming fantasy. Journal of Consumer Research, 25(3), 218-240.

Belk, R.W., Wallendorf, M. \& Sherry, J.F. (1989). The sacred and the profane in consumer behavior: Theodicy on the odyssey. Journal of Consumer Research, 16(1), 1-38. 
Beltramini, R.F. (1983). Student surrogates in consumer research. Journal of Academy of Marketing Science, 11(4), 1003-1029.

Beverland, M.B. (2005). Crafting brand authenticity: The case of luxury wine. Journal of Management Studies, 42(5), 1003-1029.

Beverland, M.B. (2006). The 'real thing': Branding authenticity in the luxury wine trade. Journal of Business Research, 59(2), 251-258.

Beverland, M.B., Farrelly, F. \& Quester, P. (2006). Brand-personal values fit and brand meanings: Exploring the role individual values play in ongoing brand loyalty in extreme sports subcultures. Advances in Consumer Research, 33(1), 21-27.

Beverland, M.B., Lindgreen, A. \& Vink, M.W. (2008). Projecting authenticity through advertising: Consumer judgments of advertisers' claims. Journal of Advertising, 37(1), 515.

Bollen, K.A. (1989). Structural equation models with latent variables, New York: John Wiley \& Sons.

Boyle, D. (2003). Authenticity: Brands, fakes, spin and the lust for real life. London: Flamingo.

Brown, S., Kozinets, R.V. \& Sherry, J.F. (2003). Teaching old brands new tricks: Retro branding and the revival of brand meaning. Journal of Marketing, 67(3), 19-33.

Calder, B.J., Phillips, L.W. \& Tybout, A.M. (1981). Designing research for application. Journal of Consumer Research, 8(2), 197-207.

Campbell, D.T. \& Fiske, D. (1959). Convergent and discriminant validation of multitraitmultimethod matrix. Psycholgical Bulletin, 56: 81-105.

Carroll, B.A. \& Swaminathan, A. (2000). Why the microbrewery movement? Organizational dynamics of resource partitioning in the U.S. brewing industry. American Journal of Sociology, 106(3): 715-762. 
Chhabra, D., Healy, R. \& Sills, E. (2003). Staged authenticity and heritage tourism. Annals of Tourism Research, 30(3): 702-719

Churchill, G.A. (1979). A paradigm for developing better measures of marketing constructs. Journal of Marketing Research, 16(1), 64-73.

Costa, J.A. \& Bamossy, G.J. (2001). Le parc Disney: Creating an 'authentic' American experience, Advances in Consumer Research, 28, 398-402.

Deci, E. \& Ryan, R. (1991). A motivational approach to self: Integration in personality. In R. Dienstbier (Eds.), Nebraska Symposium on Motivation, Vol. 38, (pp. 237-288). Lincoln: University of Nebraska Press.

Delgado-Ballester, E. (2004). Applicability of a brand trust scale across product categories. European Journal of Marketing, 38(5/6), 573-592.

Eggers, F., O’Dwyer, M., Kraus, S., Vallaster, C. \& Guldenberg, S. (2012). The impact of brand authenticity on brand trust and SME growth: A CEO perspective. Journal of World Business, http://dx.doi.org/10.1016/j.jwb.2012.07.018

Eisinga, R., Grotenhuis, M. \& Pelzer, B. (2012). The reliability of a two-item scale: Pearson, Cronbach or Spearman-Brown? International Journal of Public Health, http://dx.doi.org/10.1007/s00038-012-0416-3

Elliott, R. \& Wattanasuwan, K. (1998). Brands as symbolic resources for the construction o identity. International Journal of Advertising, 17(2): 131-144.

Fine, G.A. (2003). Crafting authenticity: The validation of identity in self-taught art. Theory and Society, 32(2), 153-180.

Firat, F.A. \& Venkatesh, A. (1995). Liberatory postmodernism and the reenchantment of consumption. Journal of Consumer Research, 22(3), 239-267.

Fishbein, M. \& Ajzen, I. (1975). Belief, attitude, intention and behavior: An introduction to theory and research. Reading: Addison-Wesley. 
Fornell, C. \& Larcker, D.F. (1981). Evaluating structural equation models with unobservable variables and measurement error. Journal of Marketing Research, 18(1), 39-50.

Fournier, S. (1998). Consumer and their brands: Developing relationship theory in consumer research. Journal of Consumer Research, 24(4), 343-374.

French, J.W. \& Michael, W.B. (1966). Standards for educational and psychological tests and manuals. Washington: American Psychological Associates.

Gerbing, D.W. \& Anderson, J.C. (1988). An updated paradigm for scale development incorporating unidimensionality and its assessment. Journal of Marketing Research, 25(2): 186-192.

Gergen, K.J. (1991). The saturated self: Dilemmas of identity in contemporary life. New York: Basic Books.

Gilmore, J.H. \&Pine, B.J. (2007). Authenticity: What consumers really want. Cambridge, MA: Harvard Business School Press.

Goffman, E. (1959). The presentation of self in everyday life. New York: Doubleday.

Grayson, K. \& Martinec, R. (2004). Consumer perceptions of iconicity and indexicality and their influence on assessments of authentic market offerings. Journal of Consumer Research, 31(2), 296-312.

Grazian, D. (2003). Blue Chicago: The search for authenticity in urban blues clubs. Chicago, IL: University of Chicago Press.

Herbig, P. \& Milewicz, J. (1993). The relationship of reputation and credibility to brand success, Journal of Consumer Marketing, 10(3), 18-24.

Holt, D.B. (2002). Why do Brands Cause Trouble? A dialectical theory of consumer culture and branding. Journal of Consumer Research, 29(1): 70-90.

Holt, D.B. (2004). How brands become icons: The principles of cultural branding. Cambridge, MA: Harvard Business School Press. 
Kates, S.M. (2004). The dynamics of brand legitimacy: An interpretive study in the gay men's community. Journal of Consumer Research, 31(2), 455-464.

Kelloway, E.K. (1998). Using LISREL for structural equation modeling: A researcher's guide. Thousand Oaks, CA: Sage Publications.

Kennick, W.E. (1985). Art and inauthenticity. Journal of Aesthetics and Art Criticism, 44(1), 3-12.

Khera, I.P. \& Benson, J.D. (1970). Are students really poor substitutes for business men in behavioral research? Journal of Marketing Research, 7(4), 529-532.

Kirmani, A. (1997). Advertising repetition as a signal of quality: If it's advertised so much, something must be wrong. Journal of Advertising, 26(3), 77-87.

Kozinets, R.V. (2001). Utopian enterprise: Articulating the meanings of Star Trek's culture of consumption. Journal of Consumer Research, 28(1), 67-88.

Kozinets, R.V. (2002). Can consumers escape the market? Emancipatory illuminations from Burning Man. Journal of Consumer Research, 29(1), 20-38.

Kozinets, R.V. \& Handelman, J.M. (2004). Adversaries of Consumption: Consumer movements, activism and ideology. Journal of Consumer Research, 31(3): 691-704.

Leigh, T.W., Peters, C. \& Shelton, J. (2006). The consumer quest for authenticity: The multiplicity of meanings within the MG subculture of consumption. Journal of the Academy of Marketing Science, 34(4), 481-493.

Lifton, R.J. (1993). The protean self: Human resilience in an age of fragmentation. New York: Basic Books.

McCracken, G. (2005). Culture and consumption II: markets, meaning, and brand management. Indiana: Indiana University Press.

Molleda, J.C. (2010). Authenticity and the construct's dimensions in public relations and communication research, Journal of Communication Management, 14(3), 223 - 236 
Moore, D.J. (2006). "Self-Brand Connections and Brand Resonance: The Role of Gender and Consumer Emotions”. In Gavan J. Fitzsimons and Vicki G. Morwitz (eds.), Association for Consumer Research, Orlando, Florida

Nunnally, J. (1978). Psychometrical Theory, $2^{\text {nd }}$ ed. New York: McGraw-Hill.

Penaloza, L. (2000). The commodification of the American West: Marketers production of cultural meanings at the trade show. Journal of Marketing, 64(4), 82-109.

Peterson, R.A. (1997). Creating country music: Fabricating authenticity. Chicago: University of Chicago Press.

Peterson, R.A. (2005). In search of authenticity. Journal of Management Studies, 42(5), 10831098.

Pocock, D. (1992). Catherine Cookson country: Tourist expectation and experience. Geography, 77(3), 236-243.

Podsakoff, P.M., MacKenzie, S.B., Lee, J.L. \& Podsakoff, N.P. (2003). Common method biases in behavioral research: A critical review of the literature and recommended remedies. Journal of Applied Psychology, 88(5): 879-903.

Postrel, V. (2003). The substance of style: How the rise of aesthetic value is remaking commerce, culture and consciousness. New York: Harper-Collins Publishers.

Putrevu, S. \& Lord, K.R. (1994). Comparative and noncomparative advertising: Attitudinal effects under cognitive and affective involvement conditions. Journal of Advertising, 23(2), $77-91$.

Rose, R.L. \& Wood, S.L. (2005). Paradox and the consumption of authenticity through reality television. Journal of Consumer Research, 32(2), 284-296.

Schwab, D.P. (1980). Construct validity in organizational behavior. In B. W. Straw, \& L. L. Cummings (Eds.), Research in Organizational Behavior (Vol. 2, pp. 2-43). Greenwich, CT: JAI Press. 
Sheldon, K., Ryan, R., Rawsthorne, L. \& Ilardi, B. (1997). Trait self and true self: Cross-role variation in the big-five personality traits and its relation with psychological authenticity and subjective well-being. Journal of Personality and Social Psychology, 73(6), 13801393.

Taylor, C. (1992), The ethics of authenticity. Cambridge: Harvard University Press.

Thompson, C.J. (2000). Postmodern consumer goals made easy!!!!. In S. Ratneshwar, D. G. Mick, \& C. Huffman (Eds.), The why of consumption: Contemporary perspectives on consumer motives, goals, and desires (pp. 120-139). London: Routledge.

Thompson, C.J., Rindfleisch, A. \& Arsel, Z. (2006). Emotional branding and the strategic value of the doppelganger brand image. Journal of Marketing, 70(1), 50-64.

Thomson, M., MacInnis, D.J. \& Park, C.W. (2005). The ties that bind: Measuring the strength of consumers' emotional attachments to brands. Journal of Consumer Psychology, 15(1), $77-91$.

Trilling, L. (1972) Sincerity and authentcity. Cambridge, MA: Harvard Business School Press.

Voss, K.E., Spangenberg, E.R. \& Grohmann, B. (2003). Measuring the hedonic and utilitarian dimensions of consumer attitude. Journal of Marketing Research, 40(3), 310-320.

Wild, J. (1965). Authentic existence: A new approach to "value theory". In J. M. Edie (Eds.), An invitation to phenomenology: Studies in the philosophies of experience (pp. 59-78). Chicago: Quadrangle Books.

Wipperfurth, A. (2005). Brand hijack: Marketing without marketing. London: Portfolio.

Yoo, B., \& Donthu, N. (2001). Developing and validating a multidimensional consumer-based brand equity scale. Journal of Business Research, 52(1), 1-14.

Zaichkowsky, J.L. (1985). Measuring the involvement construct. Journal of Consumer Research, 12(3), 341-352. 